\title{
Cutting Strategies for Casting Die Manufacturing on CNC Milling Machine
}

\author{
S. Rammohan Reddy ${ }^{1}$, R. Rama Krishna Reddy ${ }^{2}$ \\ I (M.Tech Student, Dept of Mechanical Engineering, K.S.R.M College of Engg, Kadapa, Andhra Pradesh, India) \\ ${ }^{2}$ (Associate Professor, Dept of Mechanical Engineering, K.S.R.M College of Engg, Kadapa, Andhra Pradesh, \\ India)
}

\begin{abstract}
Manufacturing of dies has been presenting greater requirements of geometrical accuracy, dimensional precision and surface quality as well as decrease in costs and manufacturing times. Although proper cutting parameter values are utilized to obtain high geometrical accuracy and surface quality, there may exist geometrical discrepancy between the designed and the manufactured surface profile of the die cavities. In milling process; cutting speed, step over and feed are the main cutting parameters and these parameters affect geometrical accuracy and surface quality of the casting die cavities. In this paper, effects of the cutting parameters on geometrical error have been examined on a representative die cavity profile. To remove undesired volume in the die cavities, available cutting strategies are investigated. Finish option for roughing and finish option for finishing are optimized to reduce the Machining time of the cutting process thereby decreasing the cost of cutting process. The cutting parameters considered are Cut Feed, Step Depth, Spindle Speed for both roughing and finishing, scan type for roughing and lace type for finishing.3D model and manufacturing process is done in parametric modeling software Pro/Engineer wildfire5.0.
\end{abstract}

Keywords: Casting Dies, Milling Process ,, roughing \& finishing of die cavity.

\section{Introduction}

1.1 Casting is a manufacturing process by which a liquid material is usually poured into a mold, which contains a hollow cavity of the desired shape, and then allowed to solidify. The solidified part is known as a casting. Casting is one of the oldest procedures done on metals. Many products are formed using this method. Here is an attempt to share the knowledge of casting dies. Casting is are of four types: sand casting, permanent mold casting, plaster casting and Die casting.

1.2 Die casting is a metal casting process that is characterized by forcing molten metal under high pressure into a mold cavity, which is machined into two hardened tool steel dies. Most die castings are made from nonferrous metals, specifically zinc, copper, aluminium, magnesium, lead, and tin based alloys..There are two basic types of die casting machines: hot-chamber machines and cold-chamber machines. Depending on the type of metal being cast, a hot- or cold-chamber machine is used.

1.2.1 Hot-Chamber Machines: In this die casting machine, the molten metal is forced under pressure (from $280-700 \mathrm{~kg} / \mathrm{sq} . \mathrm{cm}$ ) into a permanent mold or die made of steel. The chamber where the high pressure produced is contained in a molten metal bath. The pressure chamber (shot chamber) is heated to the melting temperature of the metal to be processed. Generally, a plunger is applied to exert pressure. Compressed air or some other gas under high pressure is also used.

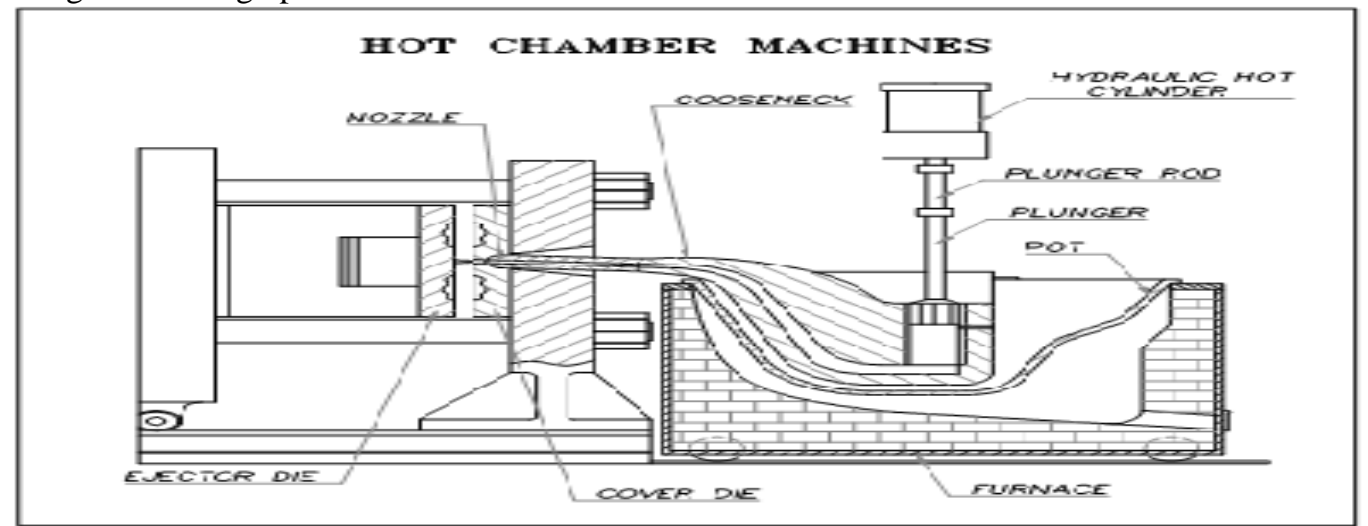

Fig. 1.1 Hot-Chamber Machine 
When the plunger is in up position the molten metal flows from the pot into the pressure cylinder through the inlet port. With the die closed and locked, the shot cylinder is actuated to move the plunger downward. As the plunger moves down, it seals off the inlet port and the molten metal is forced through the gooseneck channel and the nozzle into the die casting die. After the metal solidifies in the die cavity, the power cylinder is actuated in reverse direction pulling the plunger up. This uncovers the inlet part allowing metal to flow from the pot into the pressure cylinder. The machine is now ready for the next Machining as the two halves of the die are closed.

1.2.2 Cold-Chamber Machines: These are used when the casting alloy cannot be used in hot-chamber machines; these include aluminium, zinc alloys with a large composition of aluminium, magnesium and copper. The process for these machines start with melting the metal in a separate furnace. Then a precise amount of molten metal is transported to the cold-chamber machine where it is fed into an unheated shot chamber (or injection cylinder). This shot is then driven into the die by a hydraulic or mechanical piston.

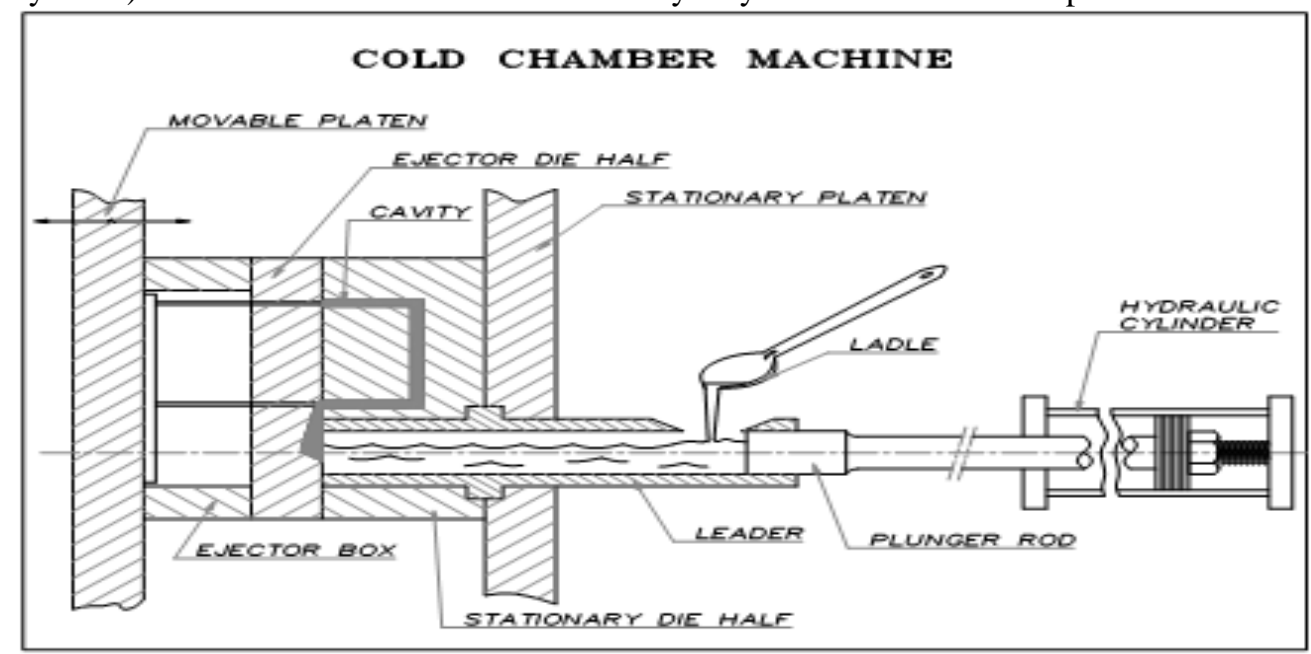

Fig. 1.2 Cold-Chamber Machine

1.3 Dies: Two dies are used in die casting; one is called the "cover die half" and the other the "ejector die half". Where they meet is called the parting line. The cover die contains the sprue (for hot-chamber machines) or shot hole (for cold-chamber machines), which allows the molten metal to flow into the dies; this feature matches up with the injector nozzle on the hot-chamber machines or the shot chamber in the cold-chamber machines. The ejector die contains the ejector pins and usually the runner, which is the path from the sprue or shot hole to the mold cavity. The cover die is secured to the stationary, or front, platen of the casting machine, while the ejector die is attached to the movable platen. The mold cavity is cut into two cavity inserts, which are separate pieces that can be replaced relatively easily and bolt into the die halves.

\subsection{Pro/ENGINEER Manufacturing (Mold Extraction)}

Computer-aided design (CAD) is the use of computer technology for the process of design and design-documentation. Pro/engineer is the standard in 3D product design, featuring industry-leading productivity tools that promote best practice in design.

Pro/Mold design is an optional module for Pro/ENGINEER that provides the tools to simulate the mold design process within Pro/ENGINEER. This module lets you create, modify, and analyze the mold components and assemblies, and quickly update them to the changes in the design model. manufacturing.

Pro/CASTING provides tools to design die assemblies and components and prepare castings for

1.5 CNC: Computerized numerical control (CNC) of milling machines is quickly becoming common place and permits far more accurate tolerances than with manual milling. CNC machines follow computer controlled machine paths with upto five axis milling and automatic cutter changing capabilities. Nowadays CNC milling technology is a basic constituent part of every modern tool making company. According to the objective model for cavity manufacturing technology, where milling tool, die and product related parameters are considered, CNC milling technology is prevalently replacing classical die sinking EDM applications.

Milling is the machining process of using rotary cutters to remove material from a workpiece advancing (or feeding) in a direction at an angle with the axis of the tool. 


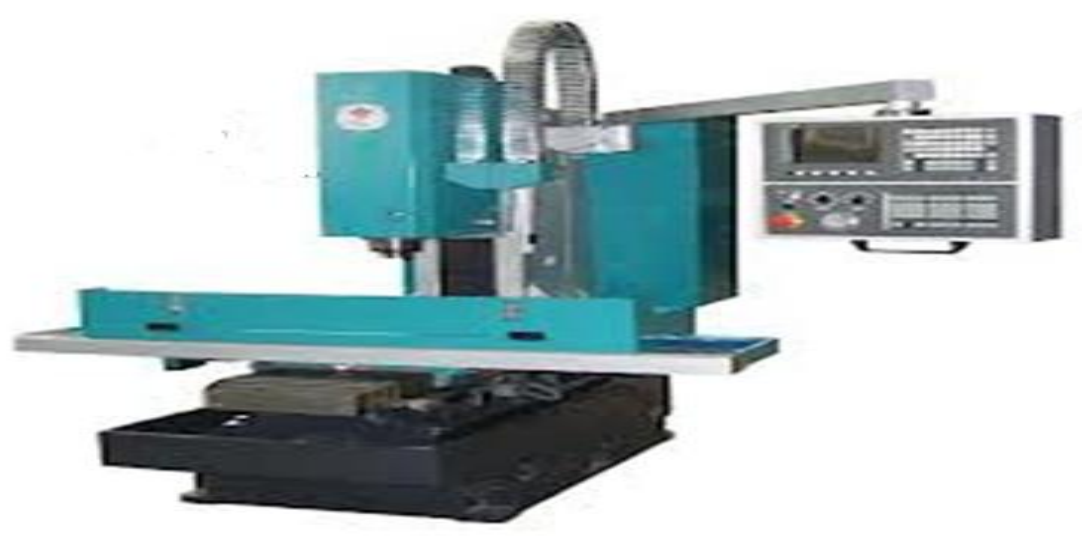

FIG 1.3 CNC Milling Machine

1.6 Component Model of BMW Car Engine Cover: The BMW car engine cover is taken for preparing Casting Die. BMW is a GERMAN company. BMW stands for Bayerische Moteren Werke, which is German, roughly translating to 'Bavarian Motor Works.'

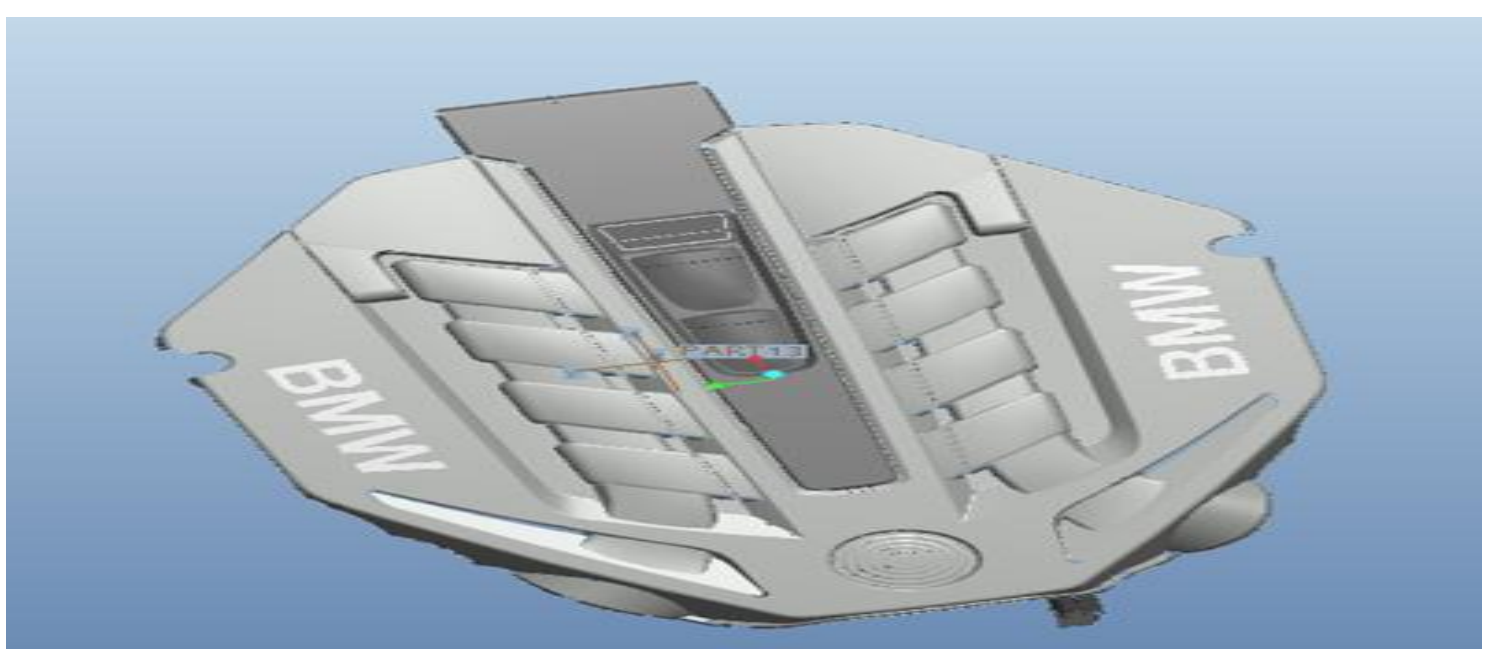

Fig. 1.4 Component Model

\section{Rough Cut Milling Of Die Cavity}

2.1 Importance of Rough Cutting Operations in Casting Die Manufacturing: Nowadays, current trend in casting die manufacturing is to produce high quality surface with an accurate geometrical properties using high speed machining centers. With the introduction of new developments in CNC milling technology, higher feed rates and cutting speeds are more and more applicable. Advances in feed rate and cutting speed provide great reductions in the production time of die cavities. However, obtaining geometrical accuracy in accordance with the product specifications is still primary objective; therefore, the most suitable cutting parameters for each operation must be carefully selected. Many researchers pay attention to optimizing finish parameters of the cutting operations but this is not completely sufficient to increase the efficiency of manufacturing processes of dies.

\subsection{Cutting Parameters for Rough Machining}

There are many parameters influencing the characteristics of milling process. However, when the cutting parameters are considered, main parameters can be classified as:

- Axial depth of cut (depth of cut) (mm)

- Radial depth of cut (step over) (mm)

- Feed rate $(\mathrm{mm} / \mathrm{min})$

- Cutting speed (r.p.m)

- Type of milling i.e. down or up milling 
Axial depth of cut is the axial engagement of the tool with respect to workpiece. Radial depth of cut or radial engagement of the tool Cutting speed is the speed difference between cutting tool and surface of the workpiece it is operating on. It depends on tool diameter and spindle speed.

In down milling the cutting edge is mainly exposed to compressive stresses, which are much more favorable for the properties of solid carbide cutters compared with the tensile stresses developed in up milling. When the cutting edge goes into cut in down milling, the chip thickness has its maximum value; on the contrary in up milling it has its minimum value. Up milling and down milling process are represented in fig 2.1.

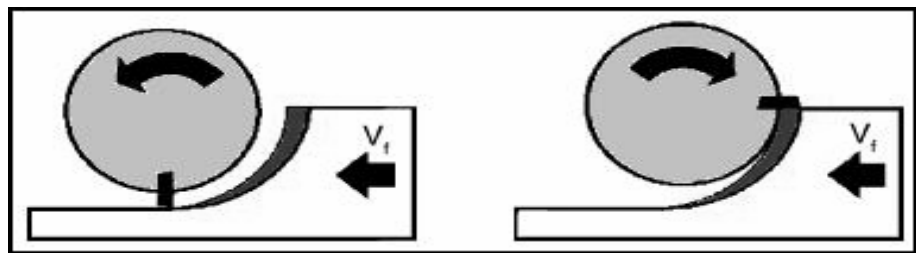

Fig. 2.1 Up milling and down milling process

2.3 ROUGH CUTTING PARAMETERS FOR THE SELECTED GEOMETRY: To define the proper diameter of the tool for the rough cutting operation, simulation package of Pro/Engineer Wildfire 5.0 is utilized. Excess volume is removed by tools having diameter of $40 \mathrm{~mm}$, and radius $5 \mathrm{~mm}$. For the determination of the axial depth of cut value, tool properties and depth of cut .

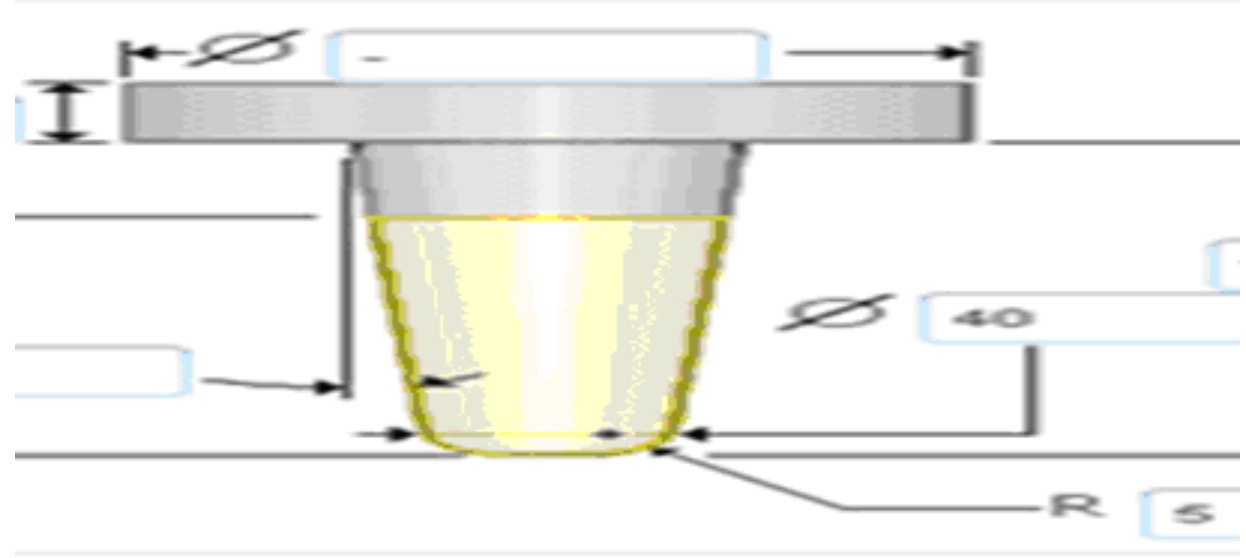

Fig. 2.2 Roghing Tool

2.4 Machining Time in Rough Machining by Changing The_SCAN TYPE

2.3.1 Available Cutting Strategies

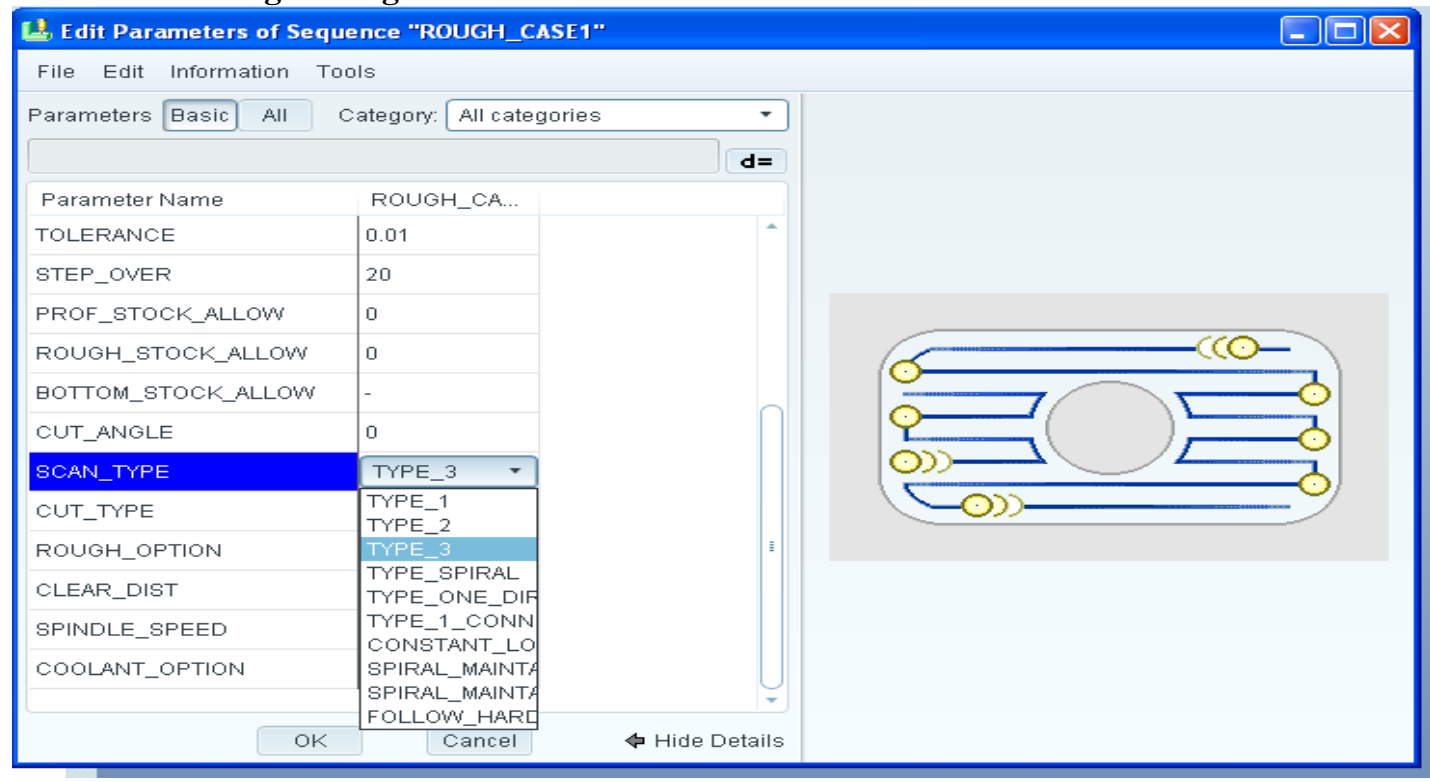


TABLE 2.1- Rough Cutting Parameters

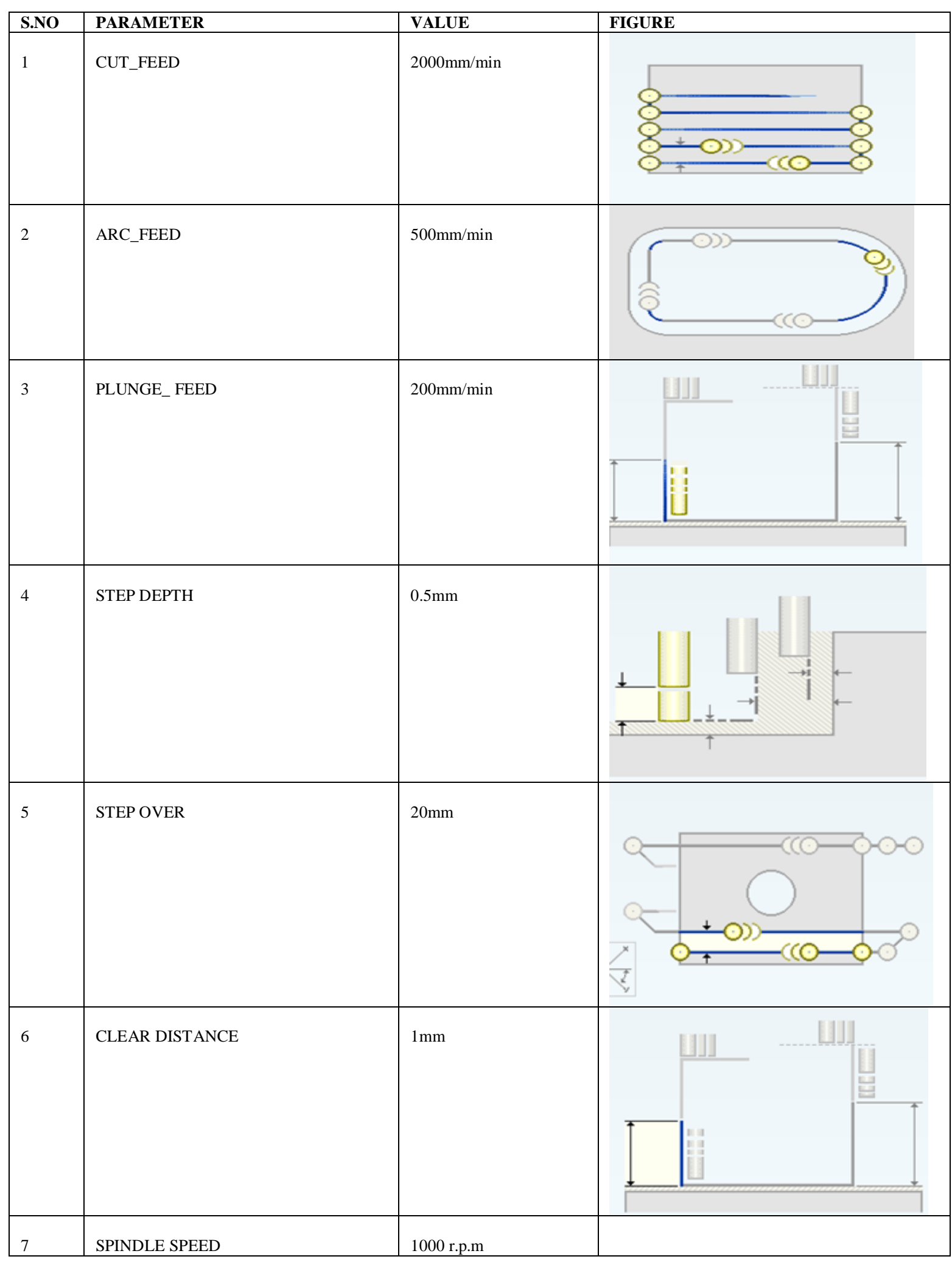




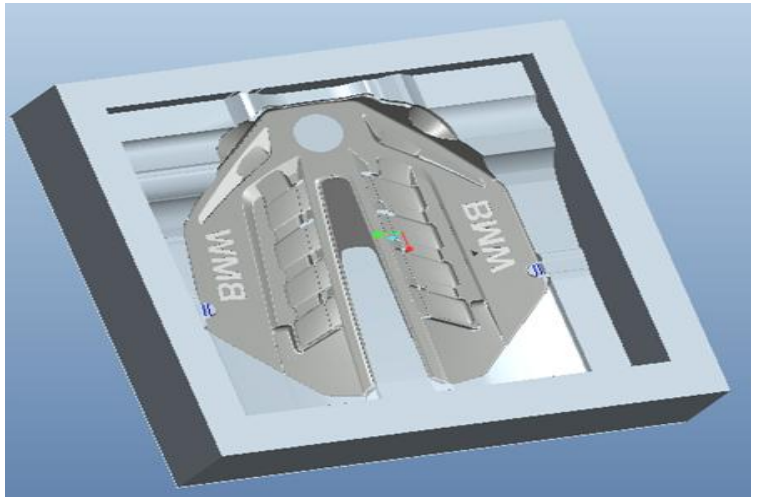

Fig. 2.3 Model of Cavity

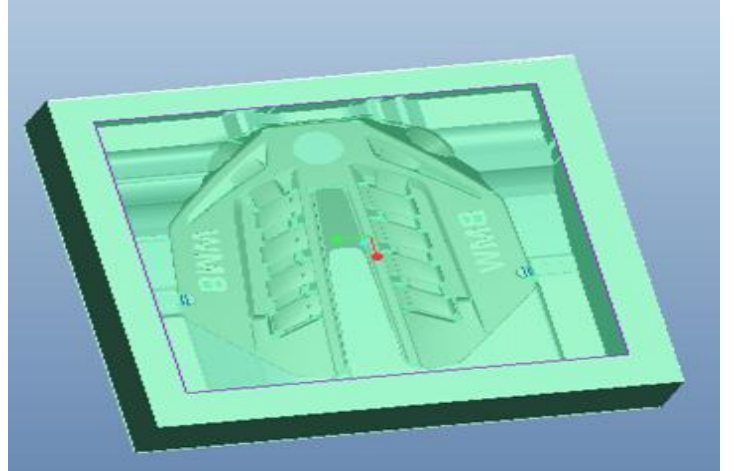

Fig. 2.4 Manufacturing Model in Pro/ENGINEER

\subsection{Result For Roughing}

The available cutting strategies of the Pro/Engineer Wildfire 5.0 are analyzed, it is realized that "Type 1" tool path is selected, the tool path which is more favorable for cutting strategies generated around all islands. Cutting tool locations of a typical tool path are illustrated in Figure 2.5 Similarly, "Type_2" provides again a scan type tool path where the cutter would go around islands. "Type_3" tool path is also a scan type tool path where the cutter would machine zone by zone. When "Type_Spiral". produces a scan type tool path where the cutter retracts upon encountering an island. As another cutting strategy, "Type_One_Dir" can be preferred to cut in one direction only, retracting and traversing to next cut. In order to maintain contour follow of the tool when entering and exiting from each cut,"Type_1_Connect" should be selected. it is observed that the "Type_1" tool is superior to other cutting strategies in terms of Machining time and tool-workpiece contact duration. Machining time of the each cutting strategy for the removal is listed Table 2.2

Ttable 2.2 Cutting Strategies vs Machining Time

\begin{tabular}{|c|c|}
\hline Cutting Strategy & MachiningTime(minutes) \\
\hline TYPE_1 & 2963.62 \\
\hline TYPE_2 & 3102.13 \\
\hline TYPE_3 & 3126.89 \\
\hline TYPE_SPIRAL & 4027.19 \\
\hline TYPE_ONE_DIRECTION & 4051.00 \\
\hline TYPE_1_CONNECT & 4238.02 \\
\hline
\end{tabular}

Fig. 2.5 Tool Play Path

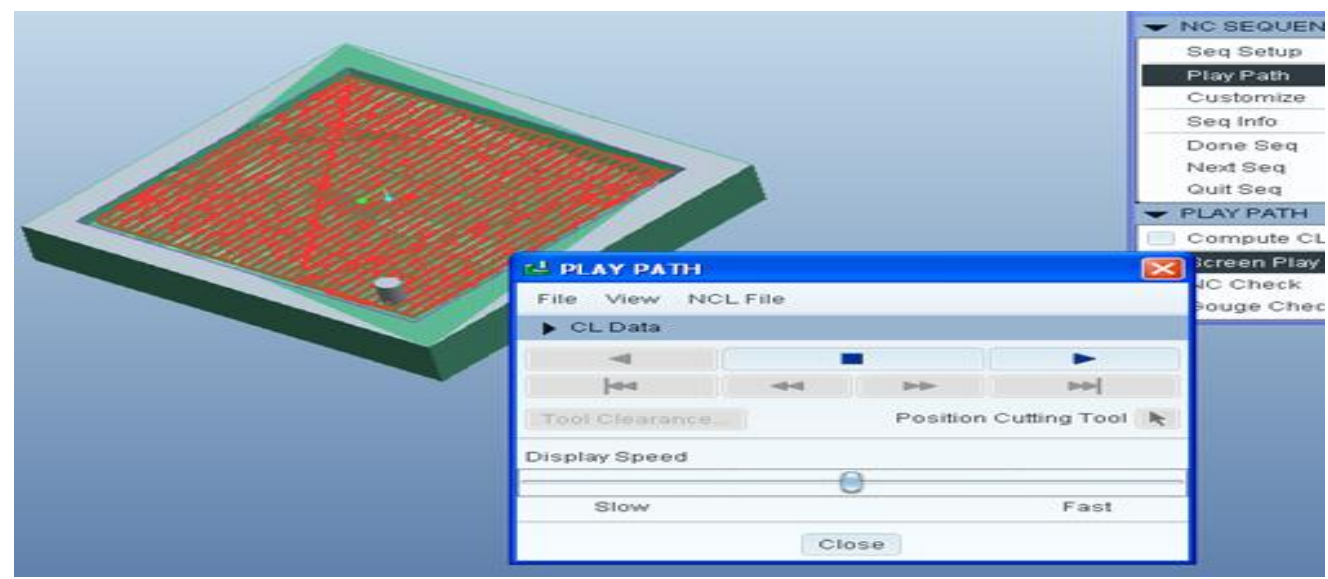

After completion of tool play path to check the required part shape is obtained or not checked by using NC check in Pro/E. it is illustrared in fig.2.6 


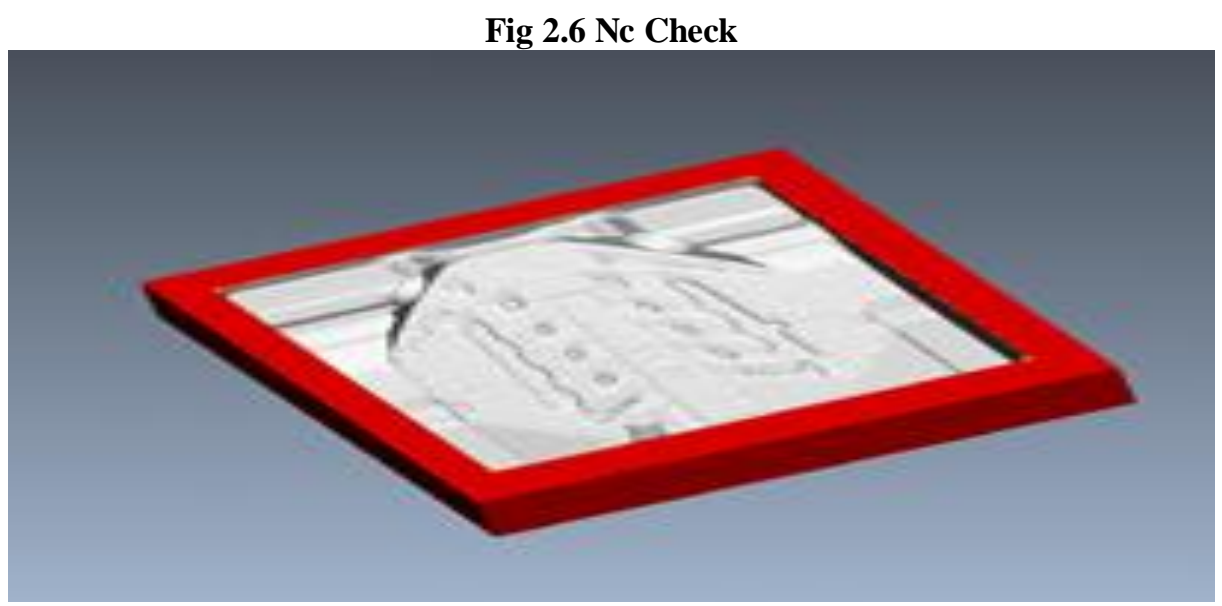

\section{Finishing Of Die Cavities}

Finishing operations are another factor when considering a switch to die casting. Ideally, the part and tool design should produce a component that's close to finish dimensions, to minimize subsequent machining. Typically, the more complex parts offer the greatest opportunity for cost savings, as die casting can often eliminate several secondary operations required to complete a machined component.

\subsection{Finish Cutting Parameters For The Selected Geometry:}

To define the proper diameter of the tool for the Finish cutting operation, simulation package of Pro/Engineer Wildfire 5.0 is utilized. The remaining material is removed by tools having diameter of $16 \mathrm{~mm}$, and radius $0.8 \mathrm{~mm}$.

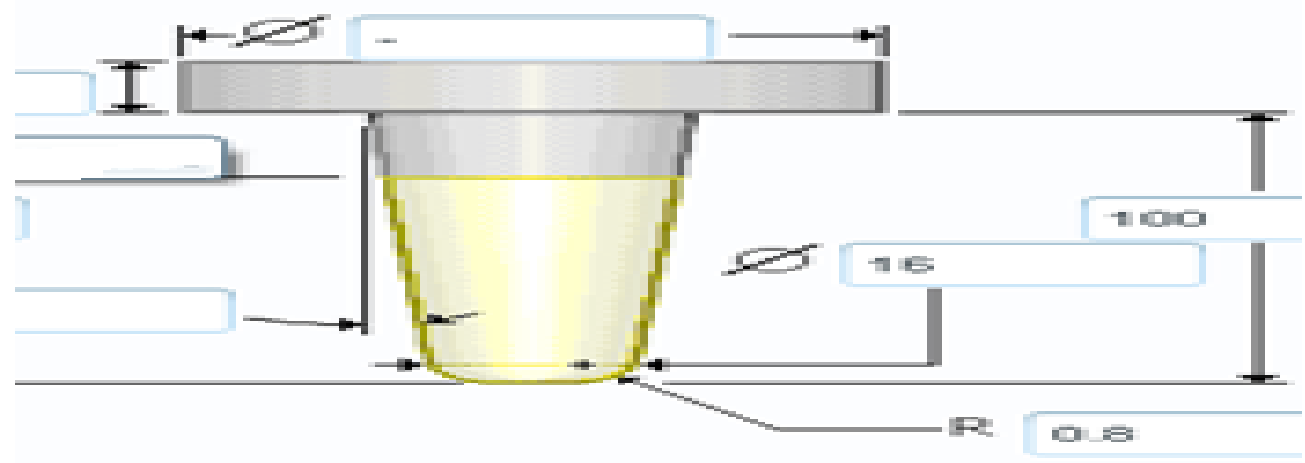

FIG 3.1 Finishing Tool

TABLE 3.1- Finishing Cutting Parameters

\begin{tabular}{|c|c|c|}
\hline S.NO & Parameter & Value \\
\hline 1 & Cut_Feed & $1000 \mathrm{~mm} / \mathrm{min}$ \\
\hline 2 & Arc_Feed & $500 \mathrm{~mm} / \mathrm{min}$ \\
\hline 3 & Plunge_Feed & $200 \mathrm{~mm} / \mathrm{min}$ \\
\hline 4 & Step Depth & $0.5 \mathrm{~mm}$ \\
\hline 5 & Step Over & $2 \mathrm{~mm}$ \\
\hline 6 & ClearDistance & $1 \mathrm{~mm}$ \\
\hline 7 & Spindle speed & 2500 r.p.m \\
\hline
\end{tabular}




\subsection{Machining Time in Finishing by Changing The_FINISH OPTION}

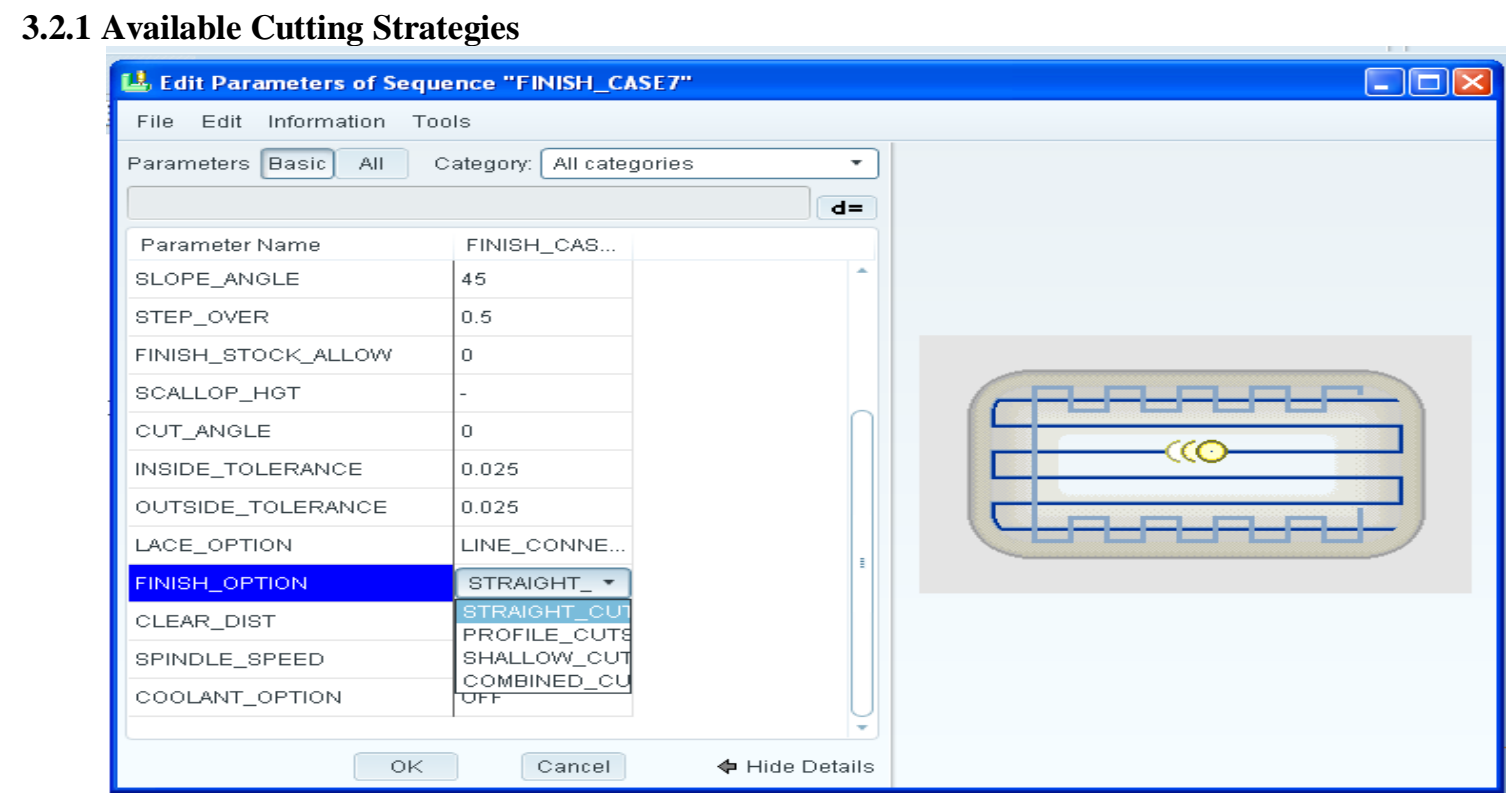

\subsection{Result For Finishing}

The available cutting strategies of the Pro/Engineer Wildfire 5.0 is shown in fig.3.1.1. these available cutting strategies are analyzed. it is realized that "profile_cuts" tool path is selected, the tool path which is more favorable for cutting strategies are generated around all islands. Cutting tool locations of a typical tool path are illustrated in Figure 3. Similarly, "straight_cuts" provides again a finish type tool path where the cutter would go around islands. "combined_cuts" tool path is also a finish type tool path where the cutter would machine zone by zone. When "shallow_cuts". produces a finish type tool path where the cutter retracts upon encountering an island. Among all these cutting strategies, it is observed that the "profile_cuts" tool is superior to other cutting strategies in terms of Machining time and tool-workpiece contact duration. Machining time of the each cutting strategy for the removal of the same amount of volume can be examined in Table 4.1.

TABLE 3.2 Cutting Strategies vs Machining Time

\begin{tabular}{|l|l|}
\hline CUTTING STRATEGY & MACHINING TIME (minutes) \\
\hline STRAIGHT_CUTS & 156.56 \\
\hline PROFILE_CUTS & 89.92 \\
\hline COMBINED_CUTS & 202.39 \\
\hline SHALLOW_CUTS & 130.10 \\
\hline
\end{tabular}

\section{Conclusion}

In this paper, the effects of cutting parameters on geometrical error have been examined on a representative die cavity profile of an automobile component. To remove undesired volume in the die cavities, available cutting strategies are investigated. Cutting strategies scan type for roughing and finish option for finishing are optimized to reduce the machining time of the cutting process thereby decreasing the cost of cutting process.

The cutting parameters considered are cut feed, step over, depth of cut, spindle speed for both roughing and finishing, scan type for roughing and finish option for finishing. Cutting strategies of Scan type for roughing are Type_1, Type_2, Type_3, Type_Spiral, Type_One_Direction and Type_1_connect. Fininish_option for finishing straight_cuts, profile_cuts, combined_cuts, shallow_cuts.

3D model and manufacturing process is done in parametric modeling software Pro/Engineer 5.0.

Roughing and finishing processes are performed on the die cavity by varying the cutting strategies scan type in roughing and finish option in finishing to determine the machining time. By observing the result, changing the scan type and finish_options of both roughing and finishing operations, the machining time is obtained as shown in table $2.2 \& 3.2$..

The optimal scan type for roughing of cavity is "Type_1" since the machining time is less and optimal finish_option for finishing is "profile_cuts" since the machining time is less . 


\section{References}

[1]. Campbell, John (2003), casting (2th ed.), Butter worth-Heinemann, ISBN

[2]. Ravi, B. (2005), Metal Casting: Computer-Aided Design and Analysis (1st ed.), PHI

[3]. Woodbury, Robert S. (1972) [1960], the Milling Machine. Cambridge, USA, and England.

[4]. Millers and Pedgen D, 2000, "Introduction to Manufacturing Simulation"

[5]. H. Juan, S.F. Yu, B.Y. Lee, "The optimal cutting-parameter selection of production cost in HSM for SKD61

[6]. tool steels", International Journal of Machine Tools \& Manufactur.

[7]. "BMW starts production of new 5 Series in India". Press Trust of India. July 13, 2010. Archived from the original on 18 July 2010. Retrieved 13 July 2010.

[8]. L.N. Lopez de Lacalle, A. Lamikiz, J.A. Sanchez, J.L. Arana, "Improving the surface finish in high speed milling of stamping dies", Journal of Materials Processing Technology .

[9]. A. Kaldos, I.F. Dagiloke, A. Boyle, "Computer aided cutting process parameter selection for high speed milling", Journal of Materials Processing Technology.

[10]. Jenq Shyong By Chen, Yung Kuo Huang, Mao-Son Chen, "Feed rate optimization and tool profile modification for the highefficiency ball end milling process", International Journal of Machine Tools \&Manufacture. 